\title{
Low Cost Method for On-Line Remote Monitoring of Power Transformers and Induction Motors
}

\author{
M. F. Cabanas, F. Pedrayes, C. Rojas, M. G. Melero, G. A. Orcajo, J. M. Cano \\ Universidad de Oviedo, Dpto. Ingeniería Eléctrica, Campus de Viesques s/n, 33204 Gijón - Asturias - España \\ http://www.dimie.uniovi.es
}

\begin{abstract}
Resumen - The application of Finite Element Method (FEM) to the analysis of the magnetic flux in power transformers and asynchronous motors has allowed the design of two new diagnosis procedures for the early detection of failures. These new methods are by its simplicity and low cost very suitable tools for remote monitoring of power transformers and motors. In the case of transformer diagnosis the installation of search coils on the machine windings for the measurement of leakage flux allows the detection of interturn shortcircuits and winding deformation. For motor condition monitoring the measurement of the magnetic flux linked by a stator tooth permits the detection of broken bars even in the case of oscillating mechanical loads. This is an important advance with respect to the conventional motor current signature analysis techniques (MCSA), which are not reliable when the driven machine provokes mechanical oscillations in the rotor shaft. The results of simulations have been validated by means of experimental measurements on actual motors, and the utility of both methods has been demonstrated.
\end{abstract}

Keywords: Finite element method, fault diagnostic, magnetic flux, induction motor, transformer, remote monitoring

\section{INTRODUCTION}

Previous research in the field of using magnetic flux for fault detection can be easily found in the scientific literature. Leakage flux has been proposed by different researchers as a tool for the detection of faults in different types of industrial devices by using different probes and measurement techniques. In fact, it has been employed for fault detection in pipes and mechanical structures by means of non-destructive tests [1], [2], in electrical circuits [3], [4] and rotating electric machinery [5]-[8]. However, to the authors aware no previous studies exist where leakage flux has been applied to insulation fault detection in power transformers.

As it will be latter shown, the use of leakage flux for diagnosis does not require the employment of expensive sensors, measurements results are very easy to analyse and its sensitivity for the detection of minor or punctual defects is high.

Broken bar detection in squirrel cage induction motors is also possible by means of leakage flux analysis [6]-[8]; however, the most commonly used techniques for the diagnosis of these faults are those based in current spectral analysis (MCSA). These methods have been studied since the early 80's [9]-[12], nevertheless, a simple and reliable fault diagnosis method capable of discriminating between the bar breakage and the influence caused by an oscillating mechanical torque is not yet available for machines operating in the steady state (in the case of using transient records of the machine start up an excellent method has been recently presented, [13], but it requires much more complex calculations).

Since industrial induction motors driving loads capable of producing torque oscillations are very common (machines coupled to the motor through gear trains, mills, fans, etc.) the utility of a new method with capability to separate load influence of the rotor fault is unquestionable.

\section{LEAKAGE FLUX FOR THE DIAGNOSIS OF POWER TRANSFORMERS}

In power transformers, not all the magnetic flux produced by the primary windings links the secondary and viceversa. A small part of the flux closes around itself through the air. This portion of flux that links only one of the windings is called leakage flux. The amount of leakage flux that is present in the transformer depends on the ratio between the magnetic circuit path and the leakage path, [14]. The lines of leakage flux are curved at the end of the windings and flow through the air in an almost parallel fashion to the axis of the winding [15]. Its degree of curvature is a function of the distance between the windings and the machines' shield and its spatial distribution is strongly influenced by the type of winding used in the transformer design [16].

The foundations of diagnosis for transformers by means of leakage flux are very simple [17]. Leakage flux in a three-phase power transformer presents a horizontal symmetry axis that passes by the medium point of the magnetic core. When an interturn shortcircuit appears or a significant winding deformation exists, the symmetry of the leakage flux is lost and under these circumstances the fault will be detectable by using the suitable sensors.

In order to verify the reliability and accuracy of the proposed method a FEM model of a 12kVA transformer previously built was developed. In this way, the analysis of leakage flux with the machine working under different conditions of load and fault level could be carried out. In order to introduce different level of faults the transformer incorporates a serial of leads connected to the windings. By short-circuiting these leads it is 
possible to apply different levels of failure to the machine. The results of the study demonstrated that leakage flux lines in a healthy machine present a symmetry axis that passes through the medium point of the magnetic core. This symmetry of the leakage flux is kept for every instance of time in the operating cycle of the machine. Fig. 1. shows the cross-section of the transformer in the region internal to the shield. The symmetry in the case of the healthy machine can be appreciated, while in the case of a faulty transformer a clearly asymmetrical distribution around the faulty zone can be observed. Two coils formed by 300 turns each can be also seen on the surface of the transformer windings. These coils will be used for the measurement of leakage flux.

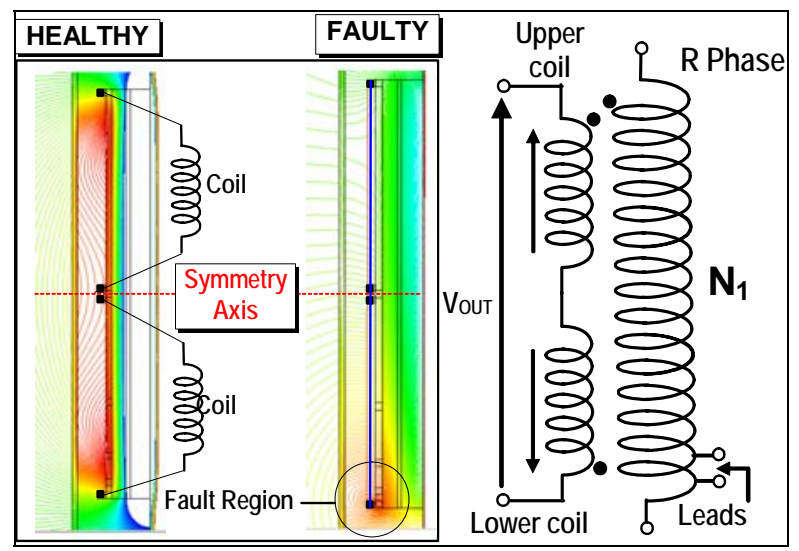

Fig. 1. Left: detail of leakage flux in the internal region of the shield before and after shortcircuiting one turn. Right; electrical diagram of the coils installed on the R-phase

Fig. 2 shows the actual measurements of $\mathrm{V}_{\text {OuT }}$ taken from the experimental transformer operating at $50 \%$ of its rated load. In this graph the capacity of the method to discriminate between the healthy and the faulty status is absolutely clear.

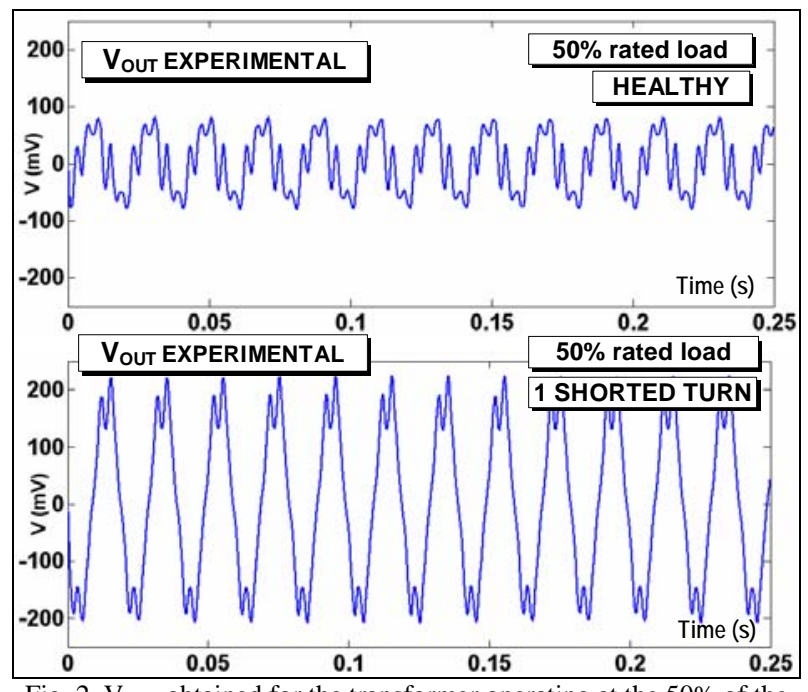

Fig. 2. $\mathrm{V}_{\text {OuT }}$ obtained for the transformer operating at the $50 \%$ of the rated load. The short-circuit test was carried out with a shorted turn in the most internal layer of the primary winding

\section{DIAGNOSIS OF BROKEN ROTOR BARS BY MEANS OF THE FLUX LINKED BY A STATOR TOOTH}

Detection of broken bars by means of MCSA methods presents certain limitations when the motor is driving a machine capable of producing an oscillating load torque. In these cases, if the load torque presents an oscillating frequency close to 2sf, s being the motor slip and $f$ the supply frequency, rotor diagnosis may be erroneous. The cause of error is the modulation produced in the motor currents by the torque oscillation. It is well known that if load torque oscillates with a frequency of $2 \mathrm{sf} \mathrm{Hz}$ this oscillation will produce the appearance of two sidebands in the current spectrum at the frequency of $(1 \pm 2 \mathrm{~s}) \mathrm{f}$. These sidebands will be superimposed to the ones used for diagnosis, thus inducing an error in the evaluation of the degree of fault.

The above method, based on the measurement of magnetic flux linked by a stator tooth allows the detection of broken rotor bars even under the influence of torque oscillations. The method is based on the measurement of the deformation caused in the magnetic poles of the motor by the breakage of a rotor bar. In a healthy symmetrical p poles machine the magnetic axis of every pole is located at 360/p geometrical degrees, and the arc of circumference comprised for any of these poles is $2 \pi \mathrm{r} / \mathrm{p}, \mathrm{r}$ being the stator internal radius. However, the magnetic poles present a different behaviour when the rotor has one or more broken rotor bars [18]. In these cases the positions of the poles' magnetic axes are no longer stable and the length of every pole fluctuates around $2 \pi \mathrm{r} / \mathrm{p}$ when the field during its rotation reaches the rotor region where the fault is present (fig. 3.).

The practical procedure for the detection of the above phenomenon is very simple. The variations caused in the length of the poles can be detected by measuring the magnetic flux of a stator tooth by means of an additional coil wound around it.

Both simulation results and laboratory measurements have demonstrated that the behaviour of magnetic poles is not affected by the presence of load torque oscillations. When load torque presents periodical oscillatory components the position of the magnetic poles as well as its length is not modified. Therefore, the detection of length fluctuations in the magnetic poles allows an unambiguous rotor diagnosis to be made.

In order to study the behaviour of the described method a FEM model of a 4 pole $11 \mathrm{~kW}$ asynchronous motor was designed. The obtained results demonstrated that a rotor bar breakage induces important changes in the magnetic flux line distribution. Fig. 3 shows the field lines and the position of every magnetic pole. In the left hand side a healthy motor operating at the rated load with a constant torque is presented. In this case no changes at the poles can be observed. In the right hand 
side the same motor is shown in the same operating conditions after breaking two bars. In this case, a clear displacement of one of the poles and a length modification in two of them can be clearly observed while the other two poles remain stable. The observation of a complete turn of the magnetic field around the rotor allowed us to verify that the abovementioned process is periodical and affects to the pole that reaches during its rotation the region of the faulty bars.

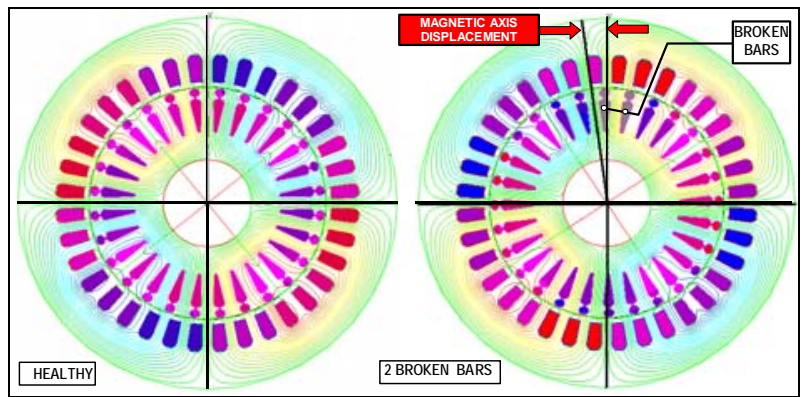

Fig. 3. Field lines and poles position at the same time instance before and after breaking two rotor bars.

While the presence of broken bars affects the length of only some of the poles, load torque oscillations affect all of them the same, therefore, no alteration appears in the magnetic field lines distribution during the rotation of the magnetic field. Fig. 4. shows this phenomenon.

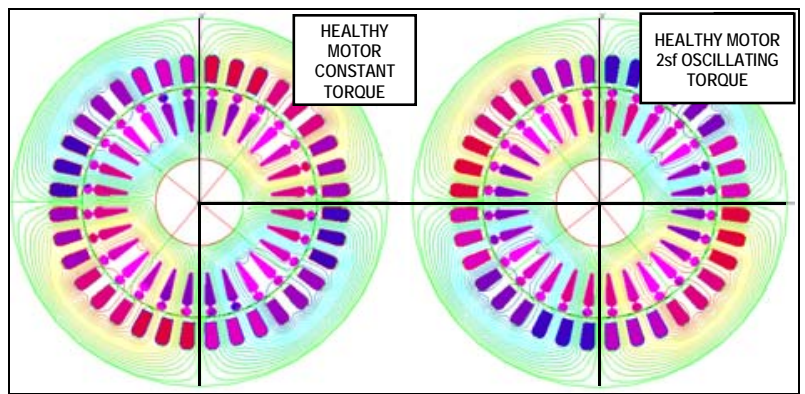

Fig. 4. Field lines and position of the poles, at the same instante with the motor operating with a constant and oscillating load torque

By simply winding a few turns coil around one of the stator teeth it is possible to measure the electromotive induced force in the coil and from it, it is also possible to calculate the airgap flux and analyse its size and behaviour. In the airgap flux waveform the times between successive zero crossings (TSZC) will not be constant for a motor with a broken bar since they depend on the pole length. However, they will be constant for a healthy machine. The following results have been obtained with an $11 \mathrm{~kW}$ motor that incorporates a 4 turns coil wound around one of its stator teeth. Fig. 5 and 6 clearly demonstrate that an oscillating component in the load torque has no influence over the TSZC's. However, if a broken bar exists the TSZC's present periodical changes. This result ratifies the simulations and validates the proposed diagnosis method.

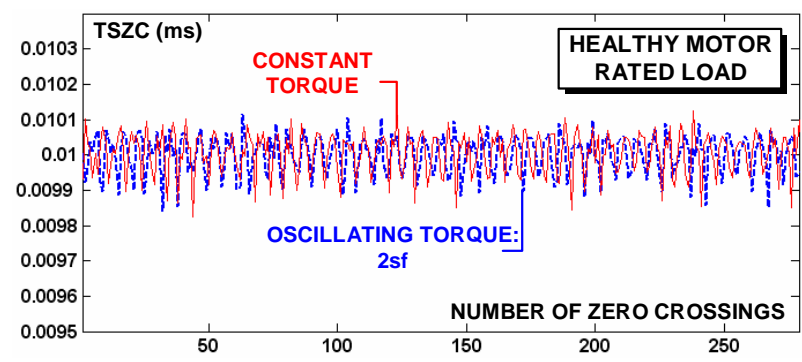

Fig. 5. TSZC's values obtained with the healthy motor operating at rated load.

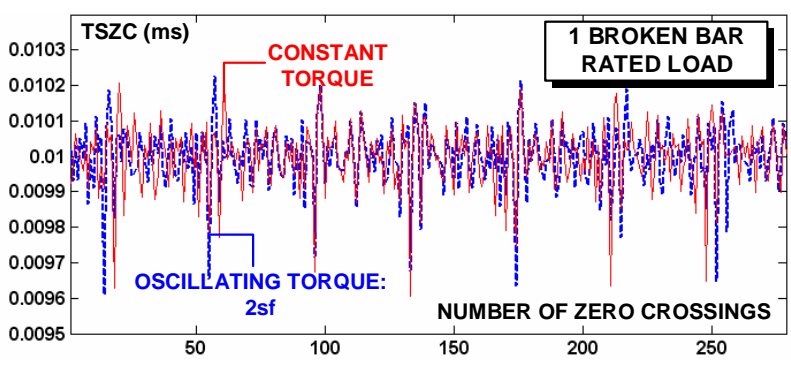

Fig. 6. TSZC's values obtained with the motor with a broken bar operating at rated load. Constant and oscillating torque

\section{REMOTE ON-LINE MONITORING}

A further aim of this study was to design the hardware needed to enable multiple machines at different locations to be monitored from a control centre. In this way, the diagnosis procedure might be applied to distribution transformers and asynchronous motors that could otherwise only receive corrective maintenance after complete breakage. Two devices are needed to perform the remote monitoring of a transformer: an electronic card that calculates on-line the DC severity factor for every pair of coils installed at the transformer windings, and a communication device to send the signal obtained to the control centre. For the remote monitoring of asynchronous motors a portable electronic device that can be permanently installed on the monitored motor and the same communications system must be used.

For transformer diagnosis a card for real-time calculation of the DC severity factor was constructed. In order to reduce the cost of the designed hardware, conventional analogue circuits were used to make the card. The card consists of three independent modules, one per each phase of the transformer. These three stages receive the voltage $V_{\text {OuT }}$ from each pair of coils installed in each phase of the transformer as input, and produce the value of the DC severity factor calculated from $\mathrm{V}_{\text {OUT }}$ as output. To do this, the three stages are divided into two blocks that perform the following functions:

- Voltage to current conversion and precision rectifying of the $\mathrm{V}_{\text {OUT }}$ signals obtained for the three phases of the transformer. 
- Low-pass filtering and current to voltage conversion of the above signals for the calculation of the DC severity factors.

The following figure is a photograph of the card that was designed, showing three independent modules, one per each phase of the transformer.

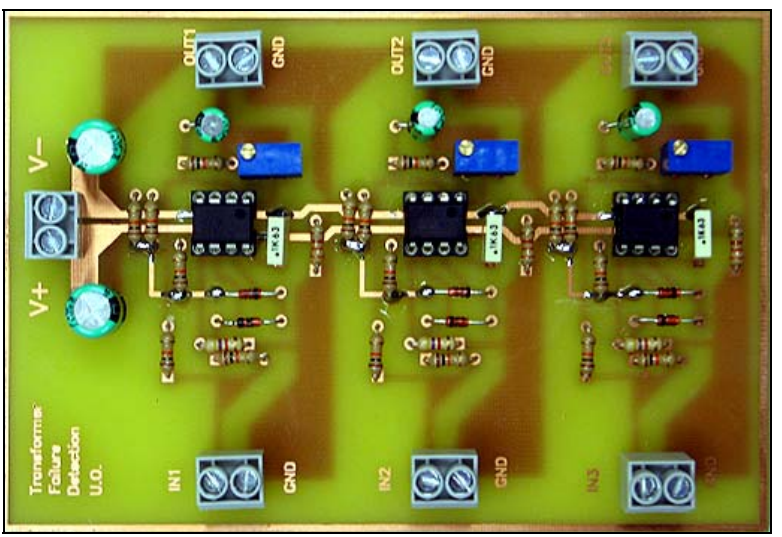

Fig.7. Electronic card for real-time calculation of the DC severity factor of a transformer

The card for the DC severity factor calculation has been designed to be used together with a communication system previously developed by our Department to perform on-line remote condition monitoring of electrical equipment. The system, called SISREM ${ }^{\mathrm{TM}}$, consists of a communication card independently powered by a $12 \mathrm{~V}$ battery charged from different external sources. The card can establish series communication with other devices via an RS485 interface.

A GSM/GPRS modem can also be used as the communication device. The communication module has been designed with 8 analogue or digital inputs, any of which can be connected to the designed diagnosis card, thereby enabling the value of the DC severity factor to be monitored remotely. Fig. 8 . shows the communication card configured with the option of GSM/GPRS modem and powered by a battery (the black device on the left of the photograph).

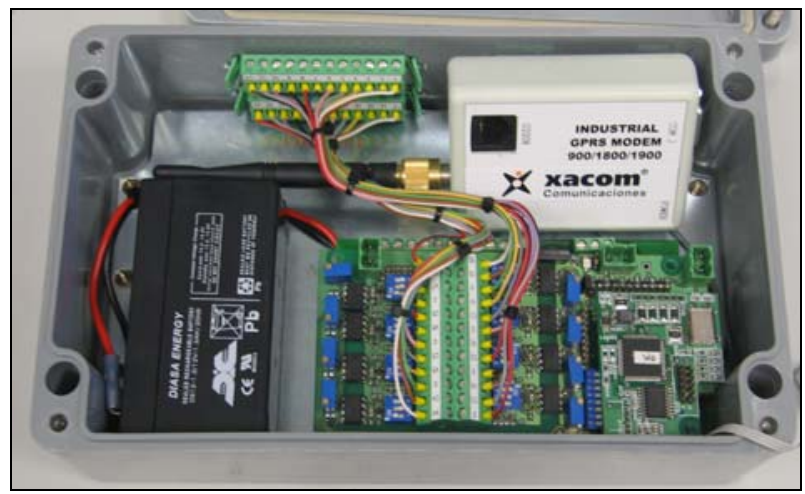

Fig. 8. Communication card for remote condition monitoring communication via GPRS
The above communications module is also compatible with the instrument designed for rotor diagnosis. In this case the designed monitoring instrument is connected to one of the available inputs of the communication card through one of its analogue inputs.

The On-Line rotor diagnosis instrument has been designed with two different functions: on the one hand it can be used independently of the communication card to perform direct fault detection of an individual motor of a set machines. On the other hand it can connected to the communication card and the results obtained for the monitored motor are sent to the remote control centre.

The operation of the instrument is based on TSZC's measurement and analysis. For these reason the values of TSZC's obtained during the test are stored in a nonvolatile EEPROM. Once the data have been recorded into the memory the equipment is able to process them and generate a field- diagnosis of motor status that is directly shown to the user in the LCD. Optionally, all the measured data can be transferred to a personal computer by means of a RS232 serial connection.

The instrument can be easily adapted and connected to the motor conventional protections in order to generate a motor stop order in the case of the presence of a rotor fault if the user has selected this option. The overall structure of the instrument designed and built is presented in figure 10.

Fig. 9 presents a view of the designed instrument. As can be concluded from the view of the photograph of the device is easily portable because of its reduced dimensions. A 9 volts battery powers the whole instrument, hence the results stored in its EEPROM can be downloaded to a personal computer after performing the test and thus motors at any location can be analysed. The instrument can also be associated to a particular motor and its conventional protection in order to trigger a stop signal in the case of a faulty rotor is detected.

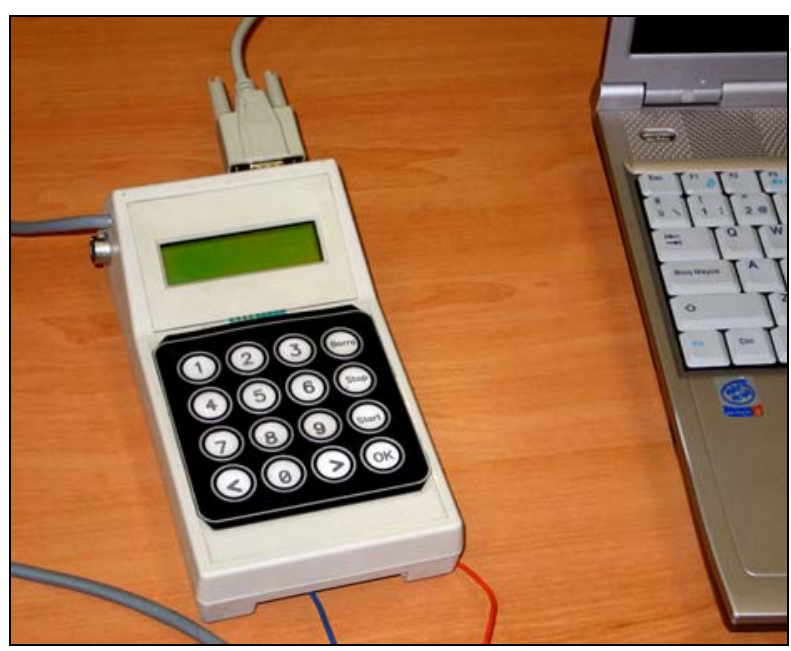

Fig. 9. External appearance of the designed instrument 


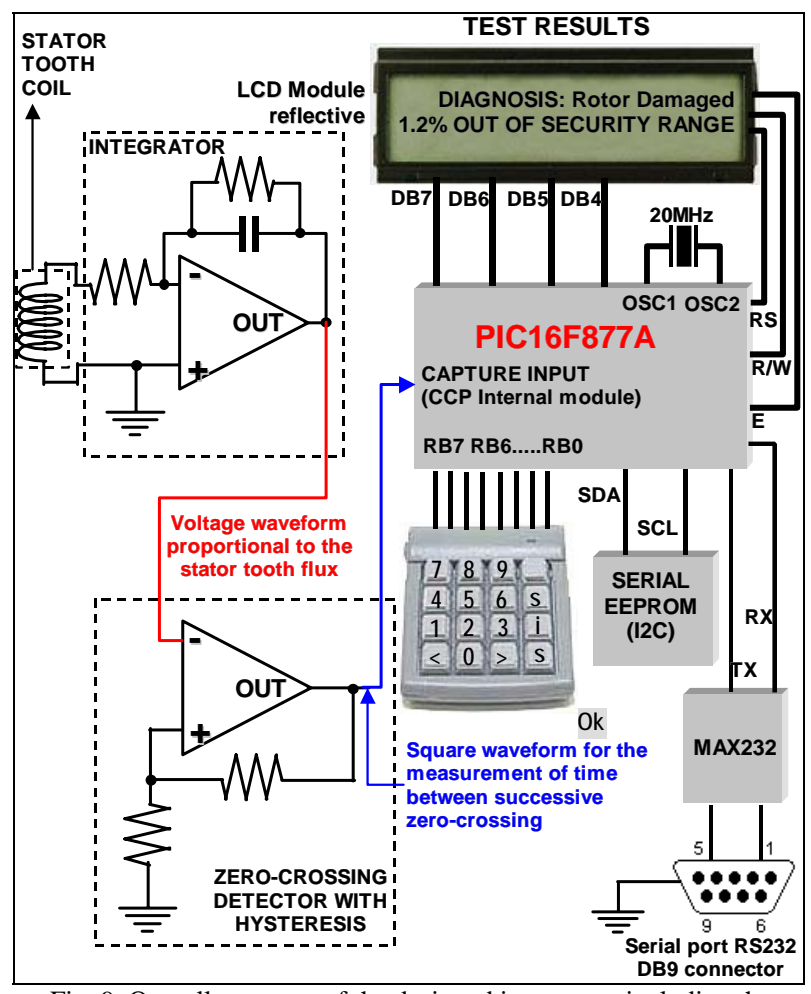

Fig. 9. Overall structure of the designed instrument including the main connections of the microcontroller

\section{CONCLUSIONS}

Two methods for the diagnosis of faults in power transformers and asynchronous motors have been developed by means of FEM simulations and experimental tests. Both methods are based on the measurement of magnetic flux and the use of very low cost sensors and very simple signal processing methods.

It has been demonstrated that for power transformer diagnosis the installation of coils at the surface of the machine's winding allows the diagnosis of interturn shortcircuits by detecting the lost of symmetry caused by the fault on leakage flux.

In the case of induction motors a simple coil wound around a stator tooth permits the detection of changes produced by the bar breakage in the length and position of the magnetic poles. The main advantage of this method is that rotor diagnosis is possible even when the motor is driving a load with an oscillating load torque. In this case a perfect discrimination between the influence of the load and the rotor fault is achieved.

Electronic equipment has been designed in order to receive the signal produced by the sensors installed at the motor and transformer. The designed devices can be directly connected to a communication module that incorporates a GPRS/GSM modem for the signal transmission, thus diagnosis can be performed from a remote control centres and applied to machine on different locations.

\section{REFERENCES}

[1] S. Yamada, M. Katou, M. Iwahara and F. P. Dawson, "Eddy current testing probe composed of planar coils," IEEE Trans. Magn., vol. 31, no. 6, Part 1, pp. 3185-3187, Nov. 1995.

[2] K. Mandal, D. Dufour and D. L. Atherton, "Use of magnetic Barkhausen noise and magnetic flux leakage signals for analysis of defects in pipeline steel," IEEE Trans. Magn., vol. 35, no. 3, Part 2, pp. 2007-2017, May 1999.

[3] S. Yamada, H. Fujiki, M. Iwahara, S. C. Mukhopadhyay and F. P. Dawson, "Investigation of printed wiring board testing by using planar coil type ECT probe,” IEEE Trans. Magn., vol. 33, no. 5, Part 1, pp. 3376-3378, Sept. 1997.

[4] S. Yamada, K. Chomsuwan, Y. Fukuda, M. Iwahara, H. Wakiwaka and S. Shoji, "Eddy-current testing probe with spin-valve type GMR sensor for printed circuit board inspection,” IEEE Trans. Magn., vol. 40, no. 4, Part 2, pp. 2676-2678, July 2004.

[5] M.S. Erlicki, Y. Porat and A. Alexandrovitz, "Leakage field changes of an induction motor as indication of nonsymmetric supply,” IEEE Trans. Ind. Gen. Appl., vol. IGA-7, no.6, pp. 713-717, Nov./Dec. 1971.

[6] M. F. Cabanas, M. G. Melero, G. A. Orcajo, F. Rodriguez Faya and J. Solares Sariego, "Experimental application of the axial leakage flux to the detection of rotor asymmetries, mechanical anomalies and interturn shortcircuits in working induction motors," in Proc. of International Conference on Electrical Machines, ICEM'98, Istanbul, 1998, pp. 420-425.

[7] J. Penman, H. Sedding, B. Lloyd and W. Fink, "Detection and Location of Interturn Shortcircuits in the Stator Winding of Operating Motors,” IEEE Trans. Energy Convers. vol. 9, no. 4, pp. 652-658, Dec. 1994.

[8] P. Vas, Parameter estimation, condition monitoring and diagnosis of electrical machines, Oxford University Press,

[9] W. Deleroi, "Squirrel cage motor with broken bar in rotor, physical phenomena and their experimental asessment", International Conference on Electrical Machines, Budapest, 1982, pp. 767-771.

[10] G. B. Kliman, R. A. Koegl, "Non-invasive detection of broken bars in operating induction machines", IEEE Transactions on Energy Conversion, Vol. 3, No. 4, December 1988.

[11] P. Vas, F Filippetti, G. Franceschini, "Transient modelling oriented to diagnostics of induction machines with rotor asymmetries”, International Conference on Electric Machines, ICEM 94, 1994 Paris.

[12] A. Bellini et Al., "ENEL'S Experience with On-line diagnosis of Large Induction Motors Cage Failures", $35^{\text {th }}$ IAS Annual Meeting and World Conference on Industrial Applications of Electrical Energy - Rome Oct 2000.

[13] J. Antonino-Daviu, M. Riera-Guasp, J. Roger-Folch and M. P. Molina, "Validation of a new method for the diagnosis of rotor bar failures via wavelet transformation in Industrial Induction Machines", IEEE Transactions on Industry Applications, Vol. 42, No 4, July/August 2006, pp. 990-996

[14] S. J. Chapman, Electric Machinery Fundamentals, International Edition, McGraw Hill, ISBN 0-07-Y66160.

[15] J. R Reitz and F. J. Milford, Foundations of Electromagnetic Theory, UTEHA, ISBN 84-274-0702.

[16] M. J. Dormont, Cálculo y Construcción de las Máquinas Eléctricas Estáticas, Universidad Politécnica de Madrid, Escuela Técnica Superior de Ingenieros Industriales. Sección de publicaciones.

[17] M. F. Cabanas, M. G. Melero, F. Pedrayes, G. Alonso, J. M. Cano and C. H. Rojas, "A New On-Line Method Based on Leakage Flux Analysis for the Early Detection and Location of Insulating failures in Power Transformers", in Proc. IEEE Symp. Diagnostics for Electrical Machines Power Electronics and Drives - SDEMPED'05, Atlanta, GA, August 2005, pp. 146-151. 
[18] M. F. Cabanas, F. Pedrayes, M. R. González, M. G. Melero, G. A. Orcajo, J. M. Cano and C. H. Rojas, “A New On-Line Method for the Early Detection of Broken Rotor Bars in Asynchronous Motors Working under Arbitrary Load Conditions”, in Proc. $35^{\text {th }}$ IAS Annual Meeting, Hong Kong Sept. 2005. 